\title{
Transcutaneous Electrical Acupoint Stimulation Attenuates Lung Injury Caused by Tourniquet- induced Limb Ischemia/reperfusion During Lower Extremity Surgery: A Randomized Controlled Trial
}

\section{Lirong Gong}

Nankai Hospital: Tianjin Hospital of Integrated Traditional Chinese and Western Medicine

Dinghuan Zhao

Tianjin Medical University

Cui Li

Nankai Hospital: Tianjin Hospital of Integrated Traditional Chinese and Western Medicine Yue Ji

Nankai Hospital: Tianjin Hospital of Integrated Traditional Chinese and Western Medicine

\section{Yongxing Kan}

Dagang Hospital of Tianjin Binhai New Area

jianbo yu ( $\sim$ yujianbo11@126.com )

Tianjin Nankai Hospital https://orcid.org/0000-0002-8674-4435

\section{Research}

Keywords: Acupuncture, Electrical stimulation, Ischemia/reperfusion, Lung injury, Inflammation

Posted Date: October 26th, 2020

DOI: https://doi.org/10.21203/rs.3.rs-95017/v1

License: (c) (1) This work is licensed under a Creative Commons Attribution 4.0 International License.

Read Full License 


\section{Abstract}

Background: Tourniquet-induced extremity ischemia-reperfusion injury is one of the major complications in patients with lower extremity surgery, while lung is the most vulnerable organ to insult subsequent to ischemia-reperfusion. Current scientific research data has shown that electric stimulation at special acupoints could suppress inflammasome activation and subsequently exert protective effects in the lungs. Thus, the effect of transcutaneous electrical acupuncture point stimulation (TEAS) on lung injury induced by limb ischemia/reperfusion remains to be elucidated.

Methods: One hundred individuals scheduled for unilateral lower extremity surgery were randomly divided into 2 groups ( $\mathrm{n}=50$ each): transcutaneous electrical acupoint stimulation group (group $\mathrm{T}$ ) and control group (group C). Patients in group T were given TEAS at FeiShu (BL13, bilateral) acupoints and ZuSanLi (ST36, non-surgical side) acupoint, while patients in group C received sham stimulation (no current) at the same acupoints for the same time as the TEAS group. Arterial blood samples were collected to assess blood gas analysis and other indicators.

Results: The TEAS group showed significant improvements in blood gas analysis. Compared with group $\mathrm{C}, \mathrm{PaO}_{2}$ and oxygenation index $(\mathrm{Ol})$ in group $\mathrm{T}$ were significantly increased at $\mathrm{T} 4$ (4h after removing the tourniquet), while $\mathrm{A}-\mathrm{aDO}_{2}$ and respiratory index (RI) were decreased at $\mathrm{T} 4$. There was an increase in the HO-1 levels in group T at T3(2h after removing the tourniquet) and T4 compared with group C. Compared with group T, SOD levels were significantly lower at T4 in group C. At T4, the levels of ICAM-1, IL-6 and IL8 were significantly lower in group T when compared to group C. At T3 and T4, IL-10 levels were higher when compared to group $\mathrm{C}$, while TNF-a levels were significantly lower.

Conclusions: Transcutaneous electrical acupoint stimulation attenuates lung injury following tourniquetinduced extremity ischemia-reperfusion in patients, and HO-1 is endowed of potential mechanism of cytoprotective effects against tourniquet-induced lung injury.

Trial registration: Chinese Clinical Trial Registry, ChiCTR-IOR-16008264. Registered 11 April 2016, http://www.chictr.org.cn/ ChiCTR-IOR-16008264

\section{Introduction}

Tourniquet placement is routinely used in orthopedic surgery to provide bloodless field and reduce intraoperative blood loss, which is an essential procedure in the process of lower extremity surgical operation including total knee arthroplasty (TKA) and fracture reduction[1-3]. However, tourniquet application leads to several complications associated with ischemia and reperfusion (I/R) injury to both local tissue and vital remote organs, even death $[4,5]$. The severity of the injury depends on the affected organs and ischemia duration of the tissue concerned[4]. Previous studies reported that I/R injury caused disturbance of cellular homeostasis in lung, and pulmonary microvascular permeability was increased following limb ischemia[6]. Reperfusion of the acute ischemic tissue triggers a potent production of reactive oxygen species (ROS) and cytokines, which promotes a proinflammatory state and subsequently 
increases lung vulnerability to further injury $[1,4,7,8]$. Although several treatment strategies have been proposed to attenuate the remote organ injury following tourniquet use, most of them were limited to animal experiments and no ideal treatment was proved to improve prognosis $[9,10]$. Therefore, to reinforce the anti-inflammatory response and endogenous protective effect would be a new strategy for improving the prognosis.

Acupuncture, a traditional Chinese medical technique, has been used in the treatment of various disorders for thousands of years. In recent decades, transcutaneous electrical acupoint stimulation (TEAS) has been often used as a complementary therapy in clinical practice with advantages of safety and being noninvasive[11]. Current scientific research data has shown that TEAS is effective for improving quality of postoperative recovery[12-14]. Evidence has revealed that electric stimulation at special acupoints could suppress the inflammasome activation and subsequently exert protective effects in the lungs[15, 16]. Our previous study also confirmed that electroacupuncture could attenuate the lung injury during endotoxic shock or I/R injury, in which the up-regulated expression of HO-1 plays a crucial role[17, 18]. But few researchers focus on I/R induced lung injury in patients undergoing lower extremity surgery and the underlying mechanism remains unclear.

Therefore, we designed a prospective double-blind randomized controlled study to test the hypothesis that the TEAS application at classical Chinese acupoints FeiShu (BL13) and ZuSanLi (ST36) can attenuate lung injury following tourniquet-induced extremity ischemia-reperfusion in patients undergoing lower extremity surgery.

\section{Materials And Methods}

\section{Trial Design}

This study was conducted as a single-center, prospective, double-blind, placebo controlled randomized study with a two-arm parallel group design to validate the protective effects of TEAS against tourniquetinduced lung injury in patients with lower extremity surgery. Immediately before induction of anesthesia(T0), immediately before removing the tourniquet (T1), and $30 \mathrm{~min}$ (T2), $2 \mathrm{~h} \mathrm{(T3)} \mathrm{and} 4 \mathrm{~h}$ (T4) after removing the tourniquet, the mean arterial pressure (MAP) and heart rate (HR) were recorded. In T1$\mathrm{T} 4$, the blood samples were collected from the radial artery for blood gas analysis. Patients breathed room air for at least 10 minutes $\left(\mathrm{FiO}_{2}=21 \%\right)$ before blood collection. Arterial partial pressure of oxygen $\left(\mathrm{PaO}_{2}\right)$ and partial pressure of carbon dioxide $\left(\mathrm{PaCO}_{2}\right)$ were recorded. Alveolar-arterial oxygen difference $\left(\mathrm{A}-\mathrm{aDO}_{2}\right)$, oxygenation index $(\mathrm{OI})$ and respiratory index $(\mathrm{RI})$ were calculated. Levels of malondialdehyde (MDA), superoxide dismutase (SOD), and nitric oxide (NO) were determined with methods of TBA (thiobarbituric acid), xanthine oxidase and nitric reductase. ET-1, MPO, XOD, ICAM-I, IL-6, IL-8, IL-10 and TNF-a level in serum were assayed by ELISA (Enzyme Linked Immunosorbent Assay). Heme oxygenase-1 (HO-1) level was measured by competitive Enzyme linked immunosorbent assay.

$\mathrm{P}_{\mathrm{A}-\mathrm{a}} \mathrm{O}_{2}=\left(\mathrm{PIO}_{2}-\mathrm{PaCO}_{2} \times 1 / \mathrm{R}\right)-\mathrm{PaO}_{2}$ 
$\mathrm{PAO}_{2}:$ Partial pressure of oxygen in alveoli

$\mathrm{PaO}_{2}$ : Arterial partial pressure of oxygen

$\mathrm{PIO}_{2}:$ Partial pressure inspired oxygen

$\mathrm{R}$ (respiratory quotient) $=0.8$

$\mathrm{PIO}_{2}=\mathrm{FIO}_{2} \times($ Atmospheric pressure-47)

$\mathrm{FIO}_{2}$ : fraction of inspired oxygen

$\mathrm{OI}=\mathrm{PaO}_{2} \div \mathrm{FiO}_{2}$

$\mathrm{RI}=\mathrm{P}_{\mathrm{A}-\mathrm{a}} \mathrm{O}_{2} \div \mathrm{PaO}_{2}$

\section{Study Subject}

One hundred patients scheduled for unilateral lower limb surgery were enrolled in this study from January 2017 to January 2019: 22 cases of ankle fracture, 6 cases of calcaneal fracture, 13 cases of knee arthroplasty for knee arthritis, 23 cases of tibial plateau fracture, 3 cases of knee neoplasm, 4 cases of tendon rupture or achilles tendon rupture, 20 cases of tibial and fibular fractures and 9 cases of patellar fracture. The inclusion criteria are: (1) adults between 20 to 60 years of age; (2) ASA class 1-2; (3) BMI 18-28 kg/m2; (4) able to give informed consent; (5) no cardiopulmonary diseases; (6) preoperative hemodynamic stability; (7) no treatment with oxidants or antioxidants one week before operation; (8) undergoing elective lower extremity surgery under spinal anesthesia. The exclusion criteria are: (1) emergency operation within 12 hours after admission; (2) refuses to participate in the study; (3) history of chronic bronchitis, emphysema or other pulmonary diseases, pulmonary dysfunction or lung injury caused by trauma; (4) history of hypertension or diabetes; (5) history of lower limb venous thrombosis or pulmonary embolism; (6) contraindications of transcutaneous electrical stimulation, including rash or local infection over the acupoint area; (7) communication disorders (language disorders, neurological history, mental disorders); (8) treatment with oxidants or antioxidants one week before operation; (9) need oxygen therapy when $\mathrm{SpO}_{2}$ less than $90 \%$; (10) hemodynamic fluctuation or other serious complications during operation; (11) failure of intraspinal anesthesia

\section{Randomization and Blindness}

100 subjects are randomly assigned to TEAS group (group T) or control group (group C) at a ratio of 1:1. Randomization was done by the researcher with 100 opaque envelopes each containing a card labeled "TEAS" or "sham" and a serial number. When the patients arrived at the operating room, sealed envelope was randomly selected. All the researchers involved work independently. Patients and data collector were blinded regarding the study.

\section{Intervention}


Before surgery, all patients were informed that they may or may not have feelings of TEAS. Before anesthesia, the acupuncturist located acupoints FeiShu (BL13, below the spine of the third thoracic vertebra on the back, 1.5 inches by side, bilateral) and ZuSanLi (ST36, downward 3 inches to the hollow of patellar ligament lateral, a horizontal finger (middle finger) from the front edge of the tibia, non-surgical side) in strict accordance with PRC National Standard GB12346-90 JingXueBuWei on all patients. Surface electrodes were placed at the specific acupoints for connection with a transcutaneous electrical stimulator (Low Frequency Electronic Pulse Therapeutic Apparatus, HuaYi G6805-1A)[19]. Subjects in group T received an altered frequency $2 / 15 \mathrm{~Hz}$ stimulation at ST36 (10-20 mA) and BL13 (20-30 mA) from 30 min before applying tourniquet till 4 hours after surgery, and the intensity was adjusted to maximum according to the participants' tolerance. The subject in group $\mathrm{C}$ received sham stimulation at the same acupoints for the same time, where surface electrodes were placed appropriately but with no current flowing in the transcutaneous electrical stimulator. The tourniquet was inflated to $65 \mathrm{kPa}$ in all subjects, and the duration of ischemia was less than $90 \mathrm{~min}$.

\section{Anesthesia}

No preoperative drugs were used. The routine preoperative preparations were performed in both groups, including fasting for at least $8 \mathrm{~h}$ before the operation, establishing venous access, and monitoring of the electrocardiogram (ECG), heart rate (HR), peripheral capillary oxygen saturation $\left(\mathrm{SpO}_{2}\right)$, and invasive blood pressure (radial artery cannulation) (BP). Patients were anesthetized by combined spinal and epidural block performed in $\mathrm{L}_{2-3}$ or $\mathrm{L}_{3-4}$ with $2.5 \mathrm{~mL}$ of $0.4 \%$ ropivacaine (SFDA approval number H20060137, Jiangsu hengrui pharmaceutical co. LTD). The sensory block was maintained below T8 level for sustaining spontaneous ventilation during the operation. To maintain hemodynamic stability, multiple electrolytes injection and hydroxyethyl starch injection were infused during the surgery. Patients who need oxygen therapy when $\mathrm{SpO}_{2}$ less than $90 \%$, failed of intraspinal anesthesia, appeared hemodynamic fluctuation or other serious complications during operation were excluded from the study. Ringer's lactate solution was infused to meet physiological requirement after surgery.

\section{Blood Sample Measurement}

Each blood sample was centrifuged to separate the serum and plasma, which were then stored at $-20^{\circ} \mathrm{C}$ for subsequent analysis. The plasma MDA was analyzed by the method of thiobarbituric acid reaction; SOD was analyzed by the Xanthinoxidase method; NO was analyzed by the method of nitric reductase method. Levels of ET-1, MPO, XOD, ICAM-I, IL-6, IL-8, IL-10 and TNF-a in serum were determined using enzyme linked immunosorbent assay with kits according to manufacturer's instructions. Heme oxygenase-1(HO-1) level was measured by competitive enzyme linked immunosorbent assay.

\section{Statistical Analysis}

All statistical analyses are performed using SPSS, version 19.0 (SPSS Inc., IL, USA). Measurement data are described with $\bar{x} \pm \mathrm{SD}$ and analyzed by t-test in the comparison among groups. The repeated measure of ANOVA was used in the comparison within groups. Enumeration data are analyzed by $\chi^{2}$ test. $P$ value $<0.05$ is considered statistically significant. 


\section{Results}

A total of 100 patients were initially enrolled in our study, and 93 completed the study. Seven patients were excluded from the study because they need general anesthesia, oxygen therapy $\left(\mathrm{SpO}_{2}\right.$ less than $90 \%$ ) or appeared hemodynamic fluctuation (Figure.1). The baseline characteristics of patients and surgeries are presented in Table 1. There were no significant differences between group $T$ and group $C$ regarding age, gender, body mass index (BMI) and ASA status. The groups were also similar in terms of tourniquet time and surgery duration.

Table 1

Baseline characteristics: patient and surgical characteristics

\begin{tabular}{|lll|}
\hline & $\begin{array}{l}\text { Group } T(\mathbf{n}=\mathbf{4 6}) \\
\text { (TEAS group) }\end{array}$ & $\begin{array}{l}\text { Group } \mathbf{C}(\mathbf{n}=\mathbf{4 7}) \\
\text { (control group) }\end{array}$ \\
\hline Age $(\mathrm{yr})$ & $35.2 \pm 10.1$ & $39.2 \pm 16.8$ \\
\hline Male/female & $30 / 16$ & $28 / 19$ \\
\hline $\mathrm{BMI}\left(\mathrm{kg} / \mathrm{m}^{2}\right)$ & $20.1 \pm 10.6$ & $22.3 \pm 9.7$ \\
\hline ASA status $(\mathrm{I} / \mathrm{II})$ & $17 / 29$ & $20 / 27$ \\
\hline Tourniquet time $(\mathrm{min})$ & $110.4 \pm 39.2$ & $106.7 \pm 31.1$ \\
\hline Surgery duration $(\mathrm{min})$ & $142.9 \pm 43.7$ & $135.2 \pm 41.9$ \\
\hline $\begin{array}{l}\text { Notes: Data are expressed as the Mean } \pm \text { SD or numbers. No statistically significant differences were } \\
\text { observed between the two groups }(\mathrm{P}>0.05) .\end{array}$ \\
\hline
\end{tabular}

\section{Assessment of Hemodynamics}

Figure 2 indicated that there was no significant difference in mean arterial pressure (MAP) or heart rate at T1-T4 compared with baseline (T0) in both groups $(P>0.05)$. Compared with group $C$, no significant difference was observed in MAP and heart rate at T0-T4 in group T (Fig. 2). Data is expressed as the Mean \pm SD (Table 2). 
Table 2

Hemodynamics of patients

\begin{tabular}{|lllllll|}
\hline & Group & T0 & T1 & T2 & T3 & T4 \\
\hline MAP $(\mathrm{mmHg})$ & Group C & $95 \pm 13$ & $93 \pm 9$ & $91 \pm 10$ & $92 \pm 9$ & $94 \pm 12$ \\
& Group T & $93 \pm 15$ & $91 \pm 11$ & $92 \pm 8$ & $93 \pm 13$ & $95 \pm 10$ \\
Heart rate $(\mathrm{bpm})$ & Group C & $82 \pm 14$ & $80 \pm 13$ & $79 \pm 11$ & $85 \pm 8$ & $78 \pm 13$ \\
& Group T & $83 \pm 11$ & $81 \pm 9$ & $78 \pm 13$ & $84 \pm 10$ & $81 \pm 14$ \\
\hline
\end{tabular}

Notes: Data are expressed as the Mean \pm SD or numbers. No statistically significant differences were observed between the two groups $(P>0.05)$.

\section{Assessment of Blood Gas Analysis}

Figure 3 indicates that $\mathrm{PaO}_{2}$ and $\mathrm{OI}$ tended to decrease, while $\mathrm{A}-\mathrm{aDO}_{2}$ and $\mathrm{RI}$ tended to increase in both groups. Compared with $\mathrm{T} 1$ (immediately before removing the tourniquet), $\mathrm{PaO}_{2}$ and $\mathrm{Ol}$ in group $\mathrm{T}$ were significantly decreased at $T 4$ in both group $C$ and group $T(P<0.05)$ (Fig. $3 A, C)$, while $A-a_{2} O_{2}$ and $R$ I were increased $(\mathrm{P}<0.05)$ (Fig. 3D,E). Compared with group $\mathrm{C}, \mathrm{PaO}_{2}$ and $\mathrm{Ol}$ in group $\mathrm{T}$ were significantly increased at T4 $(P<0.05)($ Fig. $3 A, C)$, while $A-a_{2} O_{2}$ and RI were decreased at $T 4(P<0.05)$ (Fig. 3D,E). Data is expressed as the Mean \pm SD (Table 3 ). 
Table 3

Blood gas analysis

\begin{tabular}{|c|c|c|c|c|c|}
\hline & Group & $\mathrm{T} 1$ & T2 & T3 & $\mathrm{T} 4$ \\
\hline \multirow[t]{2}{*}{$\mathrm{PaO}_{2}(\mathrm{mmHg})$} & Group C & $90.7 \pm 4.1$ & $89.4 \pm 5.1$ & $87.7 \pm 6.8$ & $77.6 \pm 6.4^{\star}$ \\
\hline & Group T & $91.4 \pm 3.7$ & $89.8 \pm 5.9$ & $88.4 \pm 6.3$ & $83.9 \pm 5.6^{\star \#}$ \\
\hline \multirow{2}{*}{$\mathrm{PaCO}_{2}(\mathrm{mmHg})$} & Group C & $40.3 \pm 2.6$ & $40.7 \pm 1.8$ & $41.0 \pm 2.8$ & $41.2 \pm 1.9$ \\
\hline & Group T & $39.0 \pm 2.8$ & $39.6 \pm 2.1$ & $40.5 \pm 2.3$ & $40.7 \pm 1.8$ \\
\hline \multirow[t]{2}{*}{$\mathrm{Ol}(\mathrm{mmHg})$} & Group C & $428.9 \pm 19.1$ & $425.8 \pm 23.6$ & $415.8 \pm 28.9$ & $363.3 \pm 29.8^{*}$ \\
\hline & Group T & $433.5 \pm 14.1$ & $426.9 \pm 28.9$ & $421.1 \pm 27.6$ & $388.1 \pm 26.3^{\star \#}$ \\
\hline \multirow[t]{2}{*}{$\mathrm{A}-\mathrm{aDO}_{2}(\mathrm{mmHg})$} & Group C & $10.6 \pm 3.6$ & $11.2 \pm 4.5$ & $12.4 \pm 5.0$ & $22.2 \pm 6.3^{*}$ \\
\hline & Group T & $10.0 \pm 3.2$ & $11.0 \pm 4.4$ & $11.9 \pm 4.9$ & $18.5 \pm 5.2^{\star \#}$ \\
\hline \multirow[t]{2}{*}{ RI } & Group C & $0.14 \pm 0.05$ & $0.14 \pm 0.04$ & $0.16 \pm 0.04$ & $0.31 \pm 0.07^{*}$ \\
\hline & Group T & $0.12 \pm 0.06$ & $0.13 \pm 0.08$ & $0.15 \pm 0.02$ & $0.23 \pm 0.09^{\star \#}$ \\
\hline
\end{tabular}

\section{Assessment of Biomarkers Measurement}

The levels of and MDA, ET-1, MPO and XOD tended to increase in both groups, while SOD and NO levels tended to decrease. MDA, MPO, XOD levels were significantly increased at T3 and T4 in both groups when compared to $\mathrm{T} 1(\mathrm{P}<0.05)$ (Fig. 4A, E, F). By contrast, the SOD levels were significantly decreased at $\mathrm{T} 3$ and $\mathrm{T} 4$ in both groups when compared to $\mathrm{T} 1(\mathrm{P}<0.05)$ (Fig. 4B). The significant difference in NO and ET-1 were found at $\mathrm{T} 4$ when compared to $\mathrm{T} 1(\mathrm{P}<0.05)(\mathrm{Fig} .4 \mathrm{C}, \mathrm{D})$. SOD level was significantly lower at $\mathrm{T} 4$ in group $C$ when compared to group $\mathrm{T}(\mathrm{P}<0.05)$ (Fig. 4B). To confirm whether $\mathrm{HO}-1$ is involved in the potential mechanism of cytoprotective effects in TEAS, we tested the level of HO-1 from T1 to T4. As shown in Fig. 4G, HO-1 tended to increase in both groups. At T3 and T4, HO-1 levels were significantly increased in both groups compared to T1. The levels of HO-1 were significantly higher at T3 and T4 in group T when compared to group $C$. Data is expressed as the Mean $\pm \operatorname{SD}($ Table 4). 
Table 4

Assessment of Biomarkers Measurement

\begin{tabular}{|c|c|c|c|c|c|}
\hline & Group & $\mathrm{T} 1$ & T2 & T3 & $\mathrm{T4}$ \\
\hline \multirow[t]{2}{*}{$\mathrm{MDA}(\mathrm{nmol} / \mathrm{ml})$} & Group C & $3.4 \pm 0.6$ & $3.5 \pm 0.7$ & $4.8 \pm 1.2^{*}$ & $\begin{array}{l}5.7 \pm \\
1.1^{*}\end{array}$ \\
\hline & GroupT & $3.2 \pm 0.5$ & $3.3 \pm 0.8$ & $4.6 \pm 1.0^{\star}$ & $\begin{array}{l}5.6 \pm \\
0.8^{*}\end{array}$ \\
\hline \multirow[t]{2}{*}{$\mathrm{SOD}(\mathrm{U} / \mathrm{ml})$} & Group C & $88.4 \pm 12.6$ & $87.7 \pm 9.8$ & $70.0 \pm 7.8^{\star}$ & $\begin{array}{l}64.2 \pm \\
8.9^{*}\end{array}$ \\
\hline & Group T & $87.0 \pm 11.8$ & $85.6 \pm 12.1$ & $73.5 \pm 9.3^{*}$ & $\begin{array}{l}72.7 \pm \\
7.5^{\star \#}\end{array}$ \\
\hline \multirow[t]{2}{*}{$\mathrm{NO}(\mathrm{nmol} / \mathrm{ml})$} & $\begin{array}{l}\text { Group } \\
\text { C }\end{array}$ & $74.3 \pm 11.4$ & $73.6 \pm 9.1$ & $72.1 \pm 7.7$ & $\begin{array}{l}57.6 \pm \\
6.6^{*}\end{array}$ \\
\hline & $\begin{array}{l}\text { Group } \\
{ }_{T}\end{array}$ & $75.2 \pm 12.4$ & $74.8 \pm 8.8$ & $73.1 \pm 8.0$ & $\begin{array}{l}59.5 \pm \\
7.6^{*}\end{array}$ \\
\hline \multirow[t]{2}{*}{ ET-1(ng/ml) } & $\begin{array}{l}\text { Group } \\
\text { C }\end{array}$ & $108.6 \pm 10.6$ & $111.7 \pm 10.3$ & $116.0 \pm 15.8$ & $\begin{array}{l}133.9 \pm \\
16.3^{*}\end{array}$ \\
\hline & $\begin{array}{l}\text { Group } \\
\mathrm{T}\end{array}$ & $107.9 \pm 10.8$ & $109.3 \pm 13.4$ & $114.2 \pm 12.3$ & $\begin{array}{l}130.7 \pm \\
15.5^{\star}\end{array}$ \\
\hline \multirow[t]{2}{*}{ MPO (U/ml) } & $\begin{array}{l}\text { Group } \\
\text { C }\end{array}$ & $5.5 \pm 0.6$ & $5.6 \pm 0.6$ & $8.2 \pm 0.9^{*}$ & $\begin{array}{l}9.6 \pm \\
1.3^{*}\end{array}$ \\
\hline & GroupT & $5.1 \pm 0.5$ & $5.1 \pm 0.5$ & $8.1 \pm 0.8^{*}$ & $\begin{array}{l}9.7 \pm \\
1.0^{*}\end{array}$ \\
\hline \multirow[t]{2}{*}{ XOD $(\mathrm{ng} / \mathrm{ml})$} & $\begin{array}{l}\text { Group } \\
\text { C }\end{array}$ & $3.51 \pm 0.38$ & $3.62 \pm 0.29$ & $5.12 \pm 0.42^{*}$ & $\begin{array}{l}5.63 \pm \\
0.39^{\star}\end{array}$ \\
\hline & $\begin{array}{l}\text { Group } \\
\mathrm{T}\end{array}$ & $3.02 \pm 0.31$ & $3.13 \pm 0.31$ & $4.98 \pm 0.29^{*}$ & $\begin{array}{l}5.52 \pm \\
0.26^{*}\end{array}$ \\
\hline \multirow[t]{2}{*}{ HO-1 (ng/ml) } & $\begin{array}{l}\text { Group } \\
\text { C }\end{array}$ & $6.5 \pm 0.8$ & $6.9 \pm 0.6$ & $9.2 \pm 1.3^{*}$ & $\begin{array}{l}11.6 \pm \\
1.5^{*}\end{array}$ \\
\hline & $\begin{array}{l}\text { Group } \\
\mathrm{T}\end{array}$ & $7.3 \pm 1.1$ & $7.6 \pm 0.9$ & $11.9 \pm 1.5^{\star \#}$ & $\begin{array}{l}13.9 \pm \\
1.8^{\star \#}\end{array}$ \\
\hline
\end{tabular}

Assessment of Proinflammatory cytokines 
We tested five proinflammatory cytokines for investigating the anti-inflammatory effect of TEAS. All proinflammatory cytokines tended to increase over time in both groups. At T3 and T4, the levels of ICAM1, IL-6, IL8, IL-10, and TNF-a were significantly increased in both groups when compared to T1 $(P<0.05)$ (Fig. 5A-E). At T4, the level of ICAM-1, IL-6 and IL8 were significantly lower in group T when compared to group $C(P<0.05)(F i g .5 A-C)$. At T3 and T4, IL-10 levels were significantly higher in group $T$ when compared to group $C(P<0.05)$ (Fig. 5D); by contrast, TNF-a levels were significantly lower in group $T$ when compared to group $C(P<0.05)$ (Fig. $5 E)$. Data is expressed as the Mean $\pm \operatorname{SD}($ Table 5$)$.

Table 5

Proinflammatory cytokine levels

\begin{tabular}{|c|c|c|c|c|c|}
\hline & Group & $\mathrm{T} 1$ & T2 & T3 & T4 \\
\hline \multirow[t]{2}{*}{ ICAM-1 (pg/ml) } & Group C & $54.1 \pm 9.4$ & $57.3 \pm 10.4$ & $70.5 \pm 11.1^{*}$ & $81.4 \pm 13.6^{*}$ \\
\hline & Group T & $55.2 \pm 8.9$ & $56.3 \pm 9.1$ & $68.2 \pm 9.9^{*}$ & $73.4 \pm 12.8^{\star \#}$ \\
\hline \multirow[t]{2}{*}{ IL-6 (pg/ml) } & Group C & $6.6 \pm 1.3$ & $7.0 \pm 1.3$ & $13.0 \pm 2.8^{*}$ & $17.9 \pm 3.3^{*}$ \\
\hline & Group T & $6.0 \pm 0.8$ & $6.5 \pm 1.4$ & $13.2 \pm 2.5^{\star}$ & $15.7 \pm 2.5^{\star \#}$ \\
\hline \multirow[t]{2}{*}{ IL-8 (pg/ml) } & Group C & $17.4 \pm 3.1$ & $18.0 \pm 3.3$ & $29.0 \pm 5.7^{*}$ & $38.1 \pm 7.3^{*}$ \\
\hline & Group T & $16.6 \pm 2.8$ & $17.5 \pm 3.4$ & $28.2 \pm 4.5^{\star}$ & $30.6 \pm 6.9^{\star \#}$ \\
\hline \multirow[t]{2}{*}{ IL-10 (pg/ml) } & Group C & $5.1 \pm 0.8$ & $6.9 \pm 1.2^{*}$ & $9.0 \pm 1.8^{\star}$ & $11.9 \pm 2.4^{\star}$ \\
\hline & Group T & $5.7 \pm 0.9$ & $7.5 \pm 1.1^{\star \#}$ & $10.9 \pm 2.3^{\star \#}$ & $13.7 \pm 3.5^{\star \#}$ \\
\hline \multirow[t]{2}{*}{ TNF-a (pg/ml) } & Group C & $23.1 \pm 4.2$ & $25.0 \pm 5.3$ & $37.2 \pm 7.1^{*}$ & $45.3 \pm 9.4^{*}$ \\
\hline & Group T & $20.6 \pm 12.9$ & $21.5 \pm 4.6$ & $31.8 \pm 6.5^{\star \#}$ & $38.1 \pm 9.9^{\star \#}$ \\
\hline
\end{tabular}

\section{Discussion}

In this single-center, prospective, double-blind, placebo controlled randomized clinical study, we demonstrated that TEAS on FeiShu (BL13) and ZuSanLi (ST36) could be a non-invasive complementary treatment to reduce lung injury following tourniquet-induced extremity ischemia-reperfusion in patients undergoing lower extremity surgery.

Limb ischemia-reperfusion injury is a common pathophysiological process mediated by multiple mechanisms and pathways. The application of tourniquet in lower extremity surgery causes limb ischemia-reperfusion injury, and at the same time, it also causes multiple distant organ damage, among 
which the lung is one of the most susceptible and harmful organs to insult due to their high perfusion, large contact area with air and sensitivity to inflammatory mediators such as oxygen free radicals[10]. Many clinical studies have documented that the electric acupuncture treatment increases pulmonary ventilation and the mechanism is related with its effect of relieving local inflammation and mitigating small airway stenosis[20,21]. Our previous research also demonstrated that electric stimulation at FeiShu (BL13) and ZuSanLi (ST36) acupoints could alleviate endotoxin shock-induced acute lung injury by reducing oxidative stress injury in rabbits[17]. In the traditional Chinese Medicine theory, ZuSanLi (ST36) acupoint is highly praised in health care and clinical treatment for modulating the Qi-blood balance. Recent study proved that acupuncture at ZuSanLi (ST36) could alleviate neuroinflammation and persistent pain[22]. In addition, FeiShu (BL13) locates along the sides of spine and close to the lungs, is the major acupoint for treating lung diseases. Study has shown that FeiShu acupoint application of cold asthma recipe has a greater advantage of absorption into blood circulation and lung distribution over non-FeiShu acupoint application[23]. Thus, we hypothesized that TEAS at FeiShu (BL13) and ZuSanLi (ST36) acupoints could protect the lungs from tourniquet related I/R injury.

Increased pulmonary vascular permeability is usually considered the major pathological feature of limb $\mathrm{I} / \mathrm{R}$-induced lung injury, leading to ventilation dysfunction. $\mathrm{A}-\mathrm{aDO}_{2}$ and $\mathrm{RI}$ can evaluate the pulmonary ventilation function reliably. In addition, $\mathrm{A}-\mathrm{aDO}_{2}$ is a sensitive indicator of pulmonary diffusion function and pulmonary gas exchange efficiency in the early stage of ventilation insufficiency[24, 25]. Ol indicates the lung ventilation function and oxygen utilization, is directly proportional to lung function. In our study, the decreased $\mathrm{Ol}$ and the increased $\mathrm{A}-\mathrm{aDO}_{2}$ and $\mathrm{RI}$ indicate the dysfunction of ventilation and oxygenation. Compared with the control group, TEAS could reduce the dysfunction of lung ventilation and oxygenation $4 \mathrm{~h}$ after removing the tourniquet(T4), which proves the exact efficacy on reducing lung injury.

The major pathological changes of limb I/R induced lung injury include extensive damage to alveolar epithelium and pulmonary vascular endothelium. However, the exact mechanism of the target cell injury remains unknown. Oxygen free radicals and lipid peroxidation damage are key factors in pathophysiological mechanism of ischemic damage. On the one hand, the integrity of cell ultrastructures and ion selectivity are destroyed by peroxidation with membrane unsaturated fatty acids; on the other hand, changes to the microenvironment of membrane binding enzyme receptors causes a series of irreversible degeneration such as intracellular calcium overload, thus resulting in the destruction of cell structure and function[26]. MDA is a lipid peroxidation product of oxygen free radicals, indicating oxidative damage in pulmonary inflammation[27]. SOD is an important enzyme for decomposing the oxygen free radicals and protects cells from injury[28]. Studies have shown that electrical stimulation could increase SOD activity, reduce ROS production and regulate balance of oxidation-antioxidation system[29,30]. The current data also suggests that TEAS increases the ability to scavenge the oxygen free radicals. Nitric oxide (NO), a pulmonary vasodilator, is proved to perform vital functions in inhibiting platelet adhesion and maintaining the endothelial structure and function. Endothelin-1 (ET-1) is an endogenous vasoconstrictor peptide that contributes to reducing endothelial injury[31]. In this study, there 
is no significant difference between control group and TEAS group, suggesting that TEAS might have less impact on pulmonary vascular permeability. During the reperfusion following severe ischemia or hypoxia, a large amount of superoxide is generated from xanthine under the action of XOD[32], and polymorphonuclearneutrophils (PMN) accumulate in large quantities[33]. PMN highly express myeloperoxidase (MPO), which reflects the aggregation of PMN in tissue. Nevertheless, excessive activation of PMNs contributes to inflammatory reaction further causes tissue injury[34]. However, we did not observe obvious change in XOD or MPO when compared with the control group, maybe because the damage was relatively mild. Furthermore, various proinflammatory cytokines are released during inflammatory reaction induced by limb I/R, mediating systemic inflammatory reaction and causing organ damage[10]. In our study, the plasma levels of ICAM-L IL-6 IL-8 IL-10 and TNF-a were increased after tourniquet release, while TEAS could reverse the inflammatory response. These results demonstrate that TEAS significantly reduces inflammation and increases the ability to scavenge the oxygen free radicals.

$\mathrm{HO}-1$, expressed in almost all mammals, is considered as an early endogenous protective kinase. $\mathrm{HO}-1$ serves as a protective gene with anti-inflammatory and anti-apoptotic properties, and has protective functions in several models of organ injury[35, 36]. Our previous study showed that HO-1/carbon monoxide protects lipopolysaccharide-exposed alveolar macrophages by reducing ROS generation[37]. Research shows that activation of PKC-a/HO-1 signaling pathway increases SOD activity and diminishes ROS content in LPS-activated alveolar macrophage cells[38]. Thus, the results in this study suggest that HO-1 is upregulated in lung injury and TEAS has a protective effect against I/R injury by possibly upregulating HO-1 expression.

We have several advantages in this study. First, it is a double-blind, placebo controlled randomized clinical study. Secondly, we use the blood gas data and several inflammatory and lung injury markers as objective indicators to evaluate the lung injury. Finally, we explore the potential mechanism for TEAS, providing a basis for further research. However, our research still has some limitations. One is the small sample size, and the other is that the mechanism of limb I/R-induced lung injury has not been fully elucidated yet. More basic and large sample clinical studies are needed in this field.

\section{Conclusions}

Transcutaneous electrical acupoint stimulation could attenuate lung injury following tourniquet-induced extremity ischemia-reperfusion in patients, and HO-1 is endowed of potential mechanism of antiinflammatory and cytoprotective effects against tourniquet-induced lung injury in TEAS.

\section{Abbreviations}

TEAS: transcutaneous electrical acupuncture point stimulation; TKA: total knee arthroplasty; I/R: ischemia and reperfusion; ROS: reactive oxygen species; MAP: mean arterial pressure; HR: heart rate; FIO2: fraction of inspired oxygen; $\mathrm{PaO2}$ : arterial partial pressure of oxygen; $\mathrm{PaCO}$ : partial pressure of carbon dioxide; A-aDO2: alveolar-arterial oxygen difference; OI: oxygenation index; RI: respiratory index; 
MDA: malondialdehyde; SOD: superoxide dismutase; NO: nitric oxide; TBA: thiobarbituric acid; ELISA: Enzyme Linked Immunosorbent Assay; HO-1: Heme oxygenase-1; PAO2: partial pressure of oxygen in alveoli; PIO2: partial pressure inspired oxygen; R: respiratory quotient; ECG: electrocardiogram; HR: heart rate; Sp02: peripheral capillary oxygen saturation; BMl: body mass index; ET-1: endothelin-1; PMN: polymorphonuclearneutrophils; MPO: myeloperoxidase

\section{Declarations}

\section{Ethics approval and consent to participate}

This study was approved by the Ethics Committee of the Dagang Hospital of Tianjin Binhai New Area of Tianjin Medical University (Ethical review number: 2017-002p). Written consent was obtained from each patient.

\section{Consent for publication}

Not applicable

\section{Availability of data and materials}

The datasets generated and/ or analyzed during the current study are available from the corresponding author upon reasonable request.

\section{Competing interests}

All authors declare no conflicts of proprietary or interest.

\section{Funding}

This study was supported by the National Natural Science Foundation of China (81601707, 81772106), and Health and Family Planning Commission of Binhai New Area,Science and Technology Research Project (2015BWKL003).

\section{Author Contributions}

J.Y. and L.G. conceived the study. L.G., D.Z and C.L. analyzed the data. Y.J., T.Y., and Y.K. performed the biological experiments and collected the data. L.G. and D.Z. drafted the manuscript. All authors read and approved the final manuscript. 
L.G., D.Z. and C.L. contributed equally to the study.

\section{Acknowledgements}

Not applicable

\section{References}

1. Leurcharusmee, P., P. Sawaddiruk, Y. Punjasawadwong, N. Chattipakorn, and S.C. Chattipakorn, The Possible Pathophysiological Outcomes and Mechanisms of Tourniquet-Induced IschemiaReperfusion Injury during Total Knee Arthroplasty. Oxid Med Cell Longev, 2018. 2018: p. 8087598.

2. Ostman, B., K. Michaelsson, H. Rahme, and L. Hillered, Tourniquet-induced ischemia and reperfusion in human skeletal muscle. Clin Orthop Relat Res, 2004(418): p. 260-5.

3. van der Merwe, J.M. and M.S. Mastel, Controversial Topics in Total Knee Arthroplasty: A Five-Year Update (Part 2). J Am Acad Orthop Surg Glob Res Rev, 2020. 4(1).

4. Gokalp, O., B. Eygi, G. Gokalp, M. Kiray, Y. Besir, S. Iscan, G. Guvendi, N.K. Yesilkaya, H. Iner, L. Yilik, and A. Gurbuz, Which Distant Organ is Most Affected by Lower Extremity Ischemia-Reperfusion? Ann Vasc Surg, 2020. 65: p. 271-281.

5. Westman, B., L. Weidenhielm, O. Rooyackers, K. Fredriksson, J. Wernerman, and F. Hammarqvist, Knee replacement surgery as a human clinical model of the effects of ischaemia/reperfusion upon skeletal muscle. Clin Sci (Lond), 2007. 113(7): p. 313-8.

6. Calikoglu, M., L. Tamer, N. Sucu, B. Coskun, B. Ercan, A. Gul, I. Calikoglu, and A. Kanik, The effects of caffeic acid phenethyl ester on tissue damage in lung after hindlimb ischemia-reperfusion. Pharmacol Res, 2003. 48(4): p. 397-403.

7. Küçükebe Ö, B., D. Özzeybek, R. Abdullayev, A. Ustaoğlu, I. Tekmen, and T. Küme, Effect of dexmedetomidine on acute lung injury in experimental ischemia-reperfusion model. Braz $\mathrm{J}$ Anesthesiol, 2017. 67(2): p. 139-146.

8. Takhtfooladi, H.A. and M.A. Takhtfooladi, Effect of curcumin on lung injury induced by skeletal muscle ischemia/reperfusion in rats. Ulus Travma Acil Cerrahi Derg, 2019. 25(1): p. 7-11.

9. Corrick, R.M., H. Tu, D. Zhang, A.N. Barksdale, R.L. Muelleman, M.C. Wadman, and Y.L. Li, Dexamethasone Protects Against Tourniquet-Induced Acute Ischemia-Reperfusion Injury in Mouse Hindlimb. Front Physiol, 2018. 9: p. 244.

10. Mansour, Z., A.L. Charles, M. Kindo, J. Pottecher, T.N. Chamaraux-Tran, A. Lejay, J. Zoll, J.P. Mazzucotelli, and B. Geny, Remote effects of lower limb ischemia-reperfusion: impaired lung, unchanged liver, and stimulated kidney oxidative capacities. Biomed Res Int, 2014. 2014: p. 392390.

11. Han, J.S. and Y.S. Ho, Global trends and performances of acupuncture research. Neurosci Biobehav Rev, 2011. 35(3): p. 680-7. 
12. Chi, Y.L., W.L. Zhang, F. Yang, F. Su, and Y.K. Zhou, Transcutaneous Electrical Acupoint Stimulation for Improving Postoperative Recovery, Reducing Stress and Inflammatory Responses in Elderly Patient Undergoing Knee Surgery. Am J Chin Med, 2019. 47(7): p. 1445-1458.

13. Man, K.M., S.S. Man, J.L. Shen, K.S. Law, S.L. Chen, W.J. Liaw, C.T. Lee, Y.J. Lee, W.L. Liao, T.M. Chang, D.X. Yu, D.C. Chen, Y.H. Chen, W.C. Chen, and S.L. Chang, Transcutaneous electrical nerve stimulation on ST36 and SP6 acupoints prevents hyperglycaemic response during anaesthesia: a randomised controlled trial. Eur J Anaesthesiol, 2011. 28(6): p. 420-6.

14. Yang, X.Y., J. Xiao, Y.H. Chen, Z.T. Wang, H.L. Wang, D.H. He, and J. Zhang, Dexamethasone alone vs in combination with transcutaneous electrical acupoint stimulation or tropisetron for prevention of postoperative nausea and vomiting in gynaecological patients undergoing laparoscopic surgery. Br J Anaesth, 2015. 115(6): p. 883-9.

15. Dhar, R., L. Zhang, Y. Li, M.N. Rana, Z. Hu, Z. Li, H. Cui, and H. Tang, Electroacupuncture ameliorates cardiopulmonary bypass induced apoptosis in lung via ROS/Nrf2/NLRP3 inflammasome pathway. Life Sci, 2019. 238: p. 116962.

16. Pan, P., X. Zhang, H. Qian, W. Shi, J. Wang, Y. Bo, and W. Li, Effects of electro-acupuncture on endothelium-derived endothelin-1 and endothelial nitric oxide synthase of rats with hypoxia-induced pulmonary hypertension. Exp Biol Med (Maywood), 2010. 235(5): p. 642-8.

17. Gong, L.R., Y.X. Kan, Y. Lian, S.A. Dong, D.H. Zhao, J. Shi, and J.B. Yu, Electroacupuncture Attenuates Limb Ischemia-Reperfusion-Induced Lung Injury Via p38 Mitogen-Activated Protein Kinase-Nuclear Factor Erythroid-2-Related Factor-2/Heme Oxygenase Pathway. J Surg Res, 2020. 246: p. 170-181.

18. Yu, J.B., S.A. Dong, X.Q. Luo, L.R. Gong, Y. Zhang, M. Wang, X.S. Cao, and D.Q. Liu, Role of HO-1 in protective effect of electro-acupuncture against endotoxin shock-induced acute lung injury in rabbits. Exp Biol Med (Maywood), 2013. 238(6): p. 705-12.

19. Wang, H., Y. Xie, Q. Zhang, N. Xu, H. Zhong, H. Dong, L. Liu, T. Jiang, Q. Wang, and L. Xiong, Transcutaneous electric acupoint stimulation reduces intra-operative remifentanil consumption and alleviates postoperative side-effects in patients undergoing sinusotomy: a prospective, randomized, placebo-controlled trial. Br J Anaesth, 2014. 112(6): p. 1075-82.

20. Li, L., J. Yu, R. Mu, and S. Dong, Clinical Effect of Electroacupuncture on Lung Injury Patients Caused by Severe Acute Pancreatitis. Evid Based Complement Alternat Med, 2017. 2017: p. 3162851.

21. Yu, J.B., S.A. Dong, L.R. Gong, M. Wang, R. Mu, C. Li, Y. Zhang, and Z.D. Li, Effect of electroacupuncture at Zusanli (ST36) and Sanyinjiao (SP6) acupoints on adrenocortical function in etomidate anesthesia patients. Med Sci Monit, 2014. 20: p. 406-12.

22. Kim, S., X. Zhang, S.C. O'Buckley, M. Cooter, J.J. Park, and A.G. Nackley, Acupuncture Resolves Persistent Pain and Neuroinflammation in a Mouse Model of Chronic Overlapping Pain Conditions. J Pain, 2018. 19(12): p. 1384.e1-1384.e14.

23. Lin, Y.Y., Y.P. Wang, H.Y. Lu, X.C. Guo, X. Liu, C.B. Wu, and Y.H. Xu, Plasma pharmacokinetics and lung distribution of tetrahydropalmatine after topical application of cold asthma recipe extract: Feishu (BL 13) versus Non-Feishu acupoint. J Ethnopharmacol, 2014. 153(2): p. 454-60. 
24. Howe, C.A., D.B. MacLeod, L. Wainman, S.J. Oliver, and P.N. Ainslie, Validation of a Noninvasive Assessment of Pulmonary Gas Exchange During Exercise in Hypoxia. Chest, 2020.

25. West, J.B., D.R. Crouch, J.M. Fine, D. Makadia, D.L. Wang, and G.K. Prisk, A New, Noninvasive Method of Measuring Impaired Pulmonary Gas Exchange in Lung Disease: An Outpatient Study. Chest, 2018. 154(2): p. 363-369.

26. Takhtfooladi, H., M. Takhtfooladi, F. Moayer, and S. Mobarakeh, Melatonin attenuates lung injury in a hind limb ischemia-reperfusion rat model. Rev Port Pneumol (2006), 2015. 21(1): p. 30-5.

27. Stopczynski, A., How the MDA Is Working Proactively to Preserve Community Water Fluoridation in Michigan. J Mich Dent Assoc, 2015. 97(4): p. 30-7.

28. Constantino, L., R.C. Gonçalves, V.R. Giombelli, C.D. Tomasi, F. Vuolo, L.W. Kist, G.M. de Oliveira, M.A. Pasquali, M.R. Bogo, T. Mauad, A. Horn, Jr., K.V. Melo, C. Fernandes, J.C. Moreira, C. Ritter, and F. DalPizzol, Regulation of lung oxidative damage by endogenous superoxide dismutase in sepsis. Intensive Care Med Exp, 2014. 2(1): p. 17.

29. Rho, S.W., G.S. Choi, E.J. Ko, S.K. Kim, Y.S. Lee, H.J. Lee, M.C. Hong, M.K. Shin, B.I. Min, H.J. Kee, C.K. Lee, and H.S. Bae, Molecular changes in remote tissues induced by electro-acupuncture stimulation at acupoint ST36. Mol Cells, 2008. 25(2): p. 178-83.

30. Zhong, S., Z. Li, L. Huan, and B.Y. Chen, Neurochemical Mechanism of Electroacupuncture: Anti-injury Effect on Cerebral Function after Focal Cerebral Ischemia in Rats. Evid Based Complement Alternat Med, 2009. 6(1): p. 51-6.

31. Perlikos, F., M. Lagiou, A. Papalois, T. Rizou, C. Kroupis, and I.K. Toumpoulis, Lazaroid (U-74389G) ameliorates lung injury due to lipid peroxidation and nitric oxide synthase-dependent reactive oxygen species generation caused by remote systematic ischemia-reperfusion following thoracoabdominal aortic occlusion. Int J Surg, 2018. 55: p. 156-161.

32. Yong, T., D. Li, M. Li, D. Liang, X. Diao, C. Deng, S. Chen, Y. Xie, D. Chen, and D. Zuo, AntiHyperuricemic Effect of 2-Hydroxy-4-methoxy-benzophenone-5-sulfonic Acid in Hyperuricemic Mice through XOD. Molecules, 2018. 23(10).

33. Patterson, E.K., D.D. Fraser, A. Capretta, R.F. Potter, and G. Cepinskas, Carbon monoxide-releasing molecule 3 inhibits myeloperoxidase (MPO) and protects against MPO-induced vascular endothelial cell activation/dysfunction. Free Radic Biol Med, 2014. 70: p. 167-73.

34. Huang, L., Y. Zhong, J.D. Ooi, Y.O. Zhou, X. Zuo, H. Luo, J.B. Chen, T. Wu, Y. Yang, T. Meng, Z. Xiao, W. Lin, X. Ao, X. Xiao, Q. Zhou, and P. Xiao, The effect of pulse methylprednisolone induction therapy in Chinese patients with dialysis-dependent MPO-ANCA associated vasculitis. Int Immunopharmacol, 2019. 76: p. 105883.

35. Chen, D., C. Wu, Y.B. Qiu, Q. Chu, X.Q. Sun, X. Wang, J.L. Chen, M.D. Lu, D.Z. Chen, and Q.F. Pang, Curcumin ameliorates hepatic chronic inflammation induced by bile duct obstruction in mice through the activation of heme oxygenase-1. Int Immunopharmacol, 2020. 78: p. 106054.

36. Yu, K., R.X. Wang, M.H. Li, T.C. Sun, Y.W. Zhou, Y.Y. Li, L.H. Sun, B.L. Zhang, Z.X. Lian, S.G. Xue, Y.X. Liu, and S.L. Deng, Melatonin Reduces Androgen Production and Upregulates Heme Oxygenase-1 
Expression in Granulosa Cells from PCOS Patients with Hypoestrogenia and Hyperandrogenia. Oxid Med Cell Longev, 2019. 2019: p. 8218650.

37. Yu, J., J. Shi, D. Wang, S. Dong, Y. Zhang, M. Wang, L. Gong, Q. Fu, and D. Liu, Heme Oxygenase1/Carbon Monoxide-regulated Mitochondrial Dynamic Equilibrium Contributes to the Attenuation of Endotoxin-induced Acute Lung Injury in Rats and in Lipopolysaccharide-activated Macrophages. Anesthesiology, 2016. 125(6): p. 1190-1201.

38. Li, X., Y. Zhang, J. Yu, R. Mu, L. Wu, J. Shi, L. Gong, and D. Liu, Activation of protein kinase C-a/heme oxygenase-1 signaling pathway improves mitochondrial dynamics in lipopolysaccharide-activated NR8383 cells. Exp Ther Med, 2018. 16(2): p. 1529-1537.

\section{Figures}

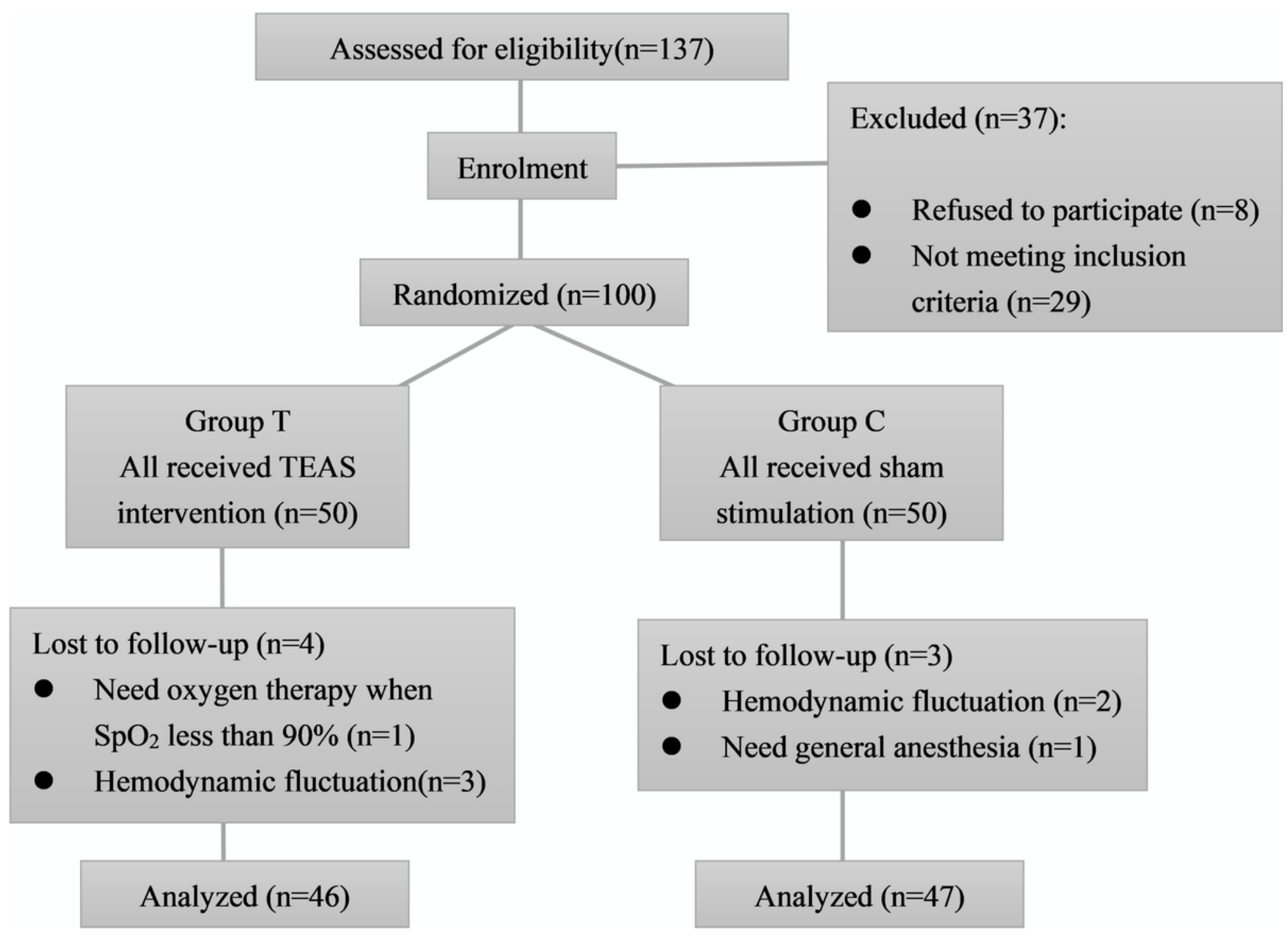

Figure 1

Flow chart of participants throughout the study 
A

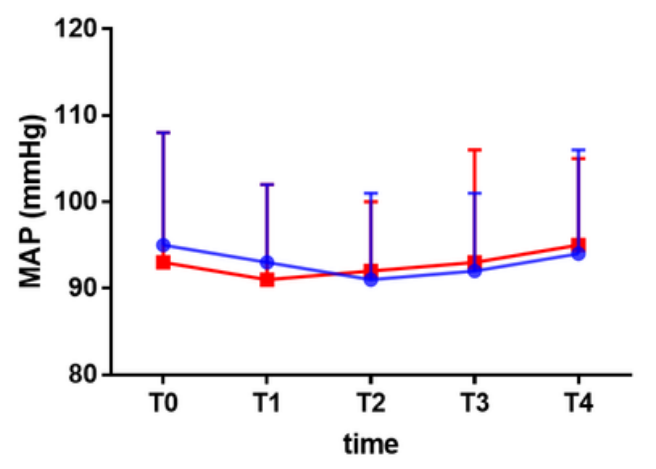

B

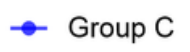

- Group T

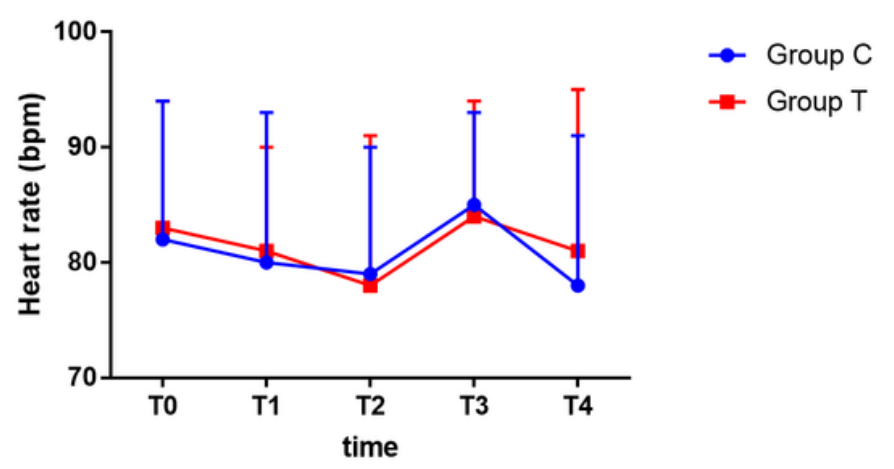

\section{Figure 2}

Changes of hemodynamics over time. Changes in (A) MAP (mean arterial pressure) and (B) heart rate in transcutaneous electrical nerve stimulation (TEAS) group (Group T) and control group (Group C). Immediately before induction of anesthesia(T0), immediately before removing the tourniquet(T1),30 min(T2), 2 (T3) and 4 h(T4) after removing the tourniquet. No statistically significant differences were observed between the two groups $(P>0.05)$ 
A

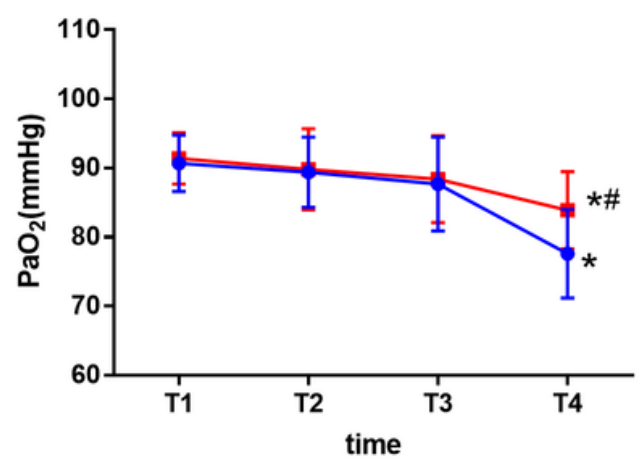

C

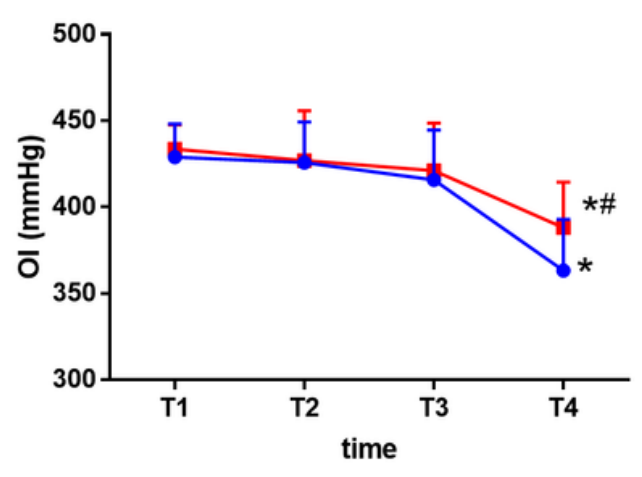

E

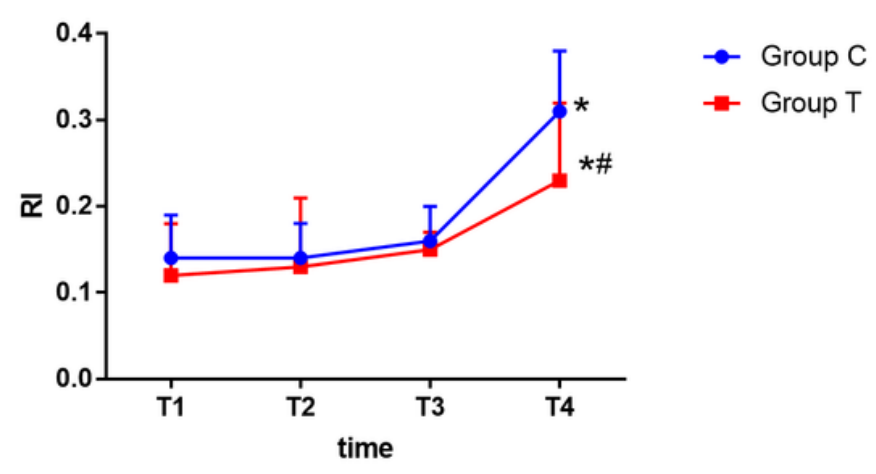

$\rightarrow$ Group C

$\rightarrow$ Group T
B

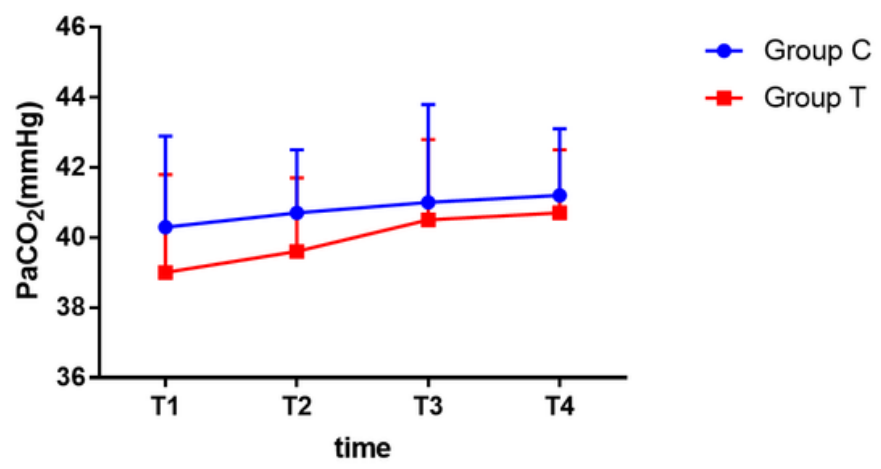

D

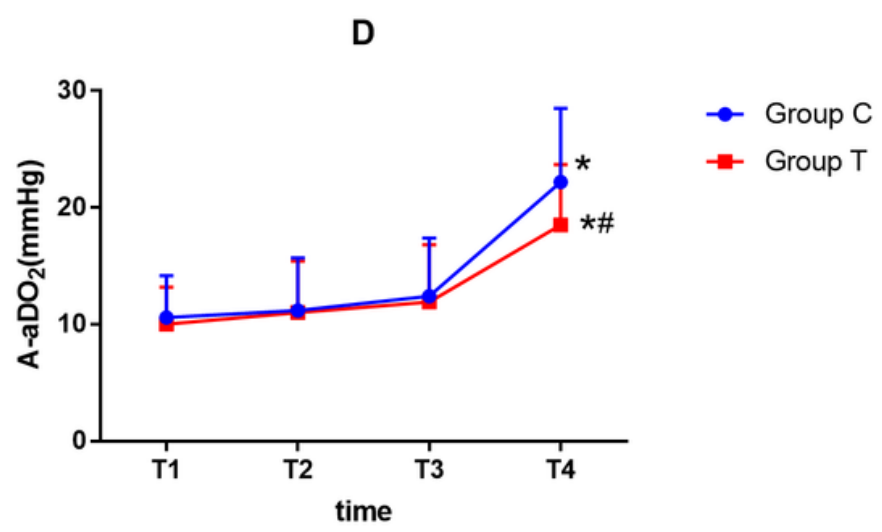

\section{Figure 3}

Changes of blood gas analysis over time. Changes in (A) PaO2(arterial partial pressure of oxygen), (B) PaCO2(arterial partial pressure of carbon dioxide), (C) Ol (oxygenation index), (D) A-aDO2 (alveolararterial oxygen tension difference) and (E) RI (respiratory index) in transcutaneous electrical nerve stimulation (TEAS) group (Group T) and control group (Group C). Immediately before removing the tourniquet(T1),30 $\min (\mathrm{T} 2), 2$ (T3) and $4 \mathrm{~h}(\mathrm{~T} 4)$ after removing the tourniquet. ${ }^{*}<0.05$, as compared to $\mathrm{T} 1$, $\# \mathrm{P}<0.05$ as compared to group $\mathrm{C}$ 
A

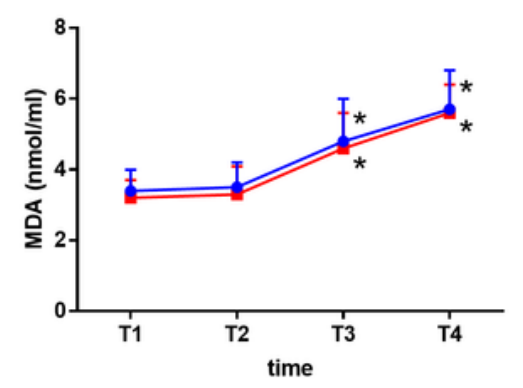

C

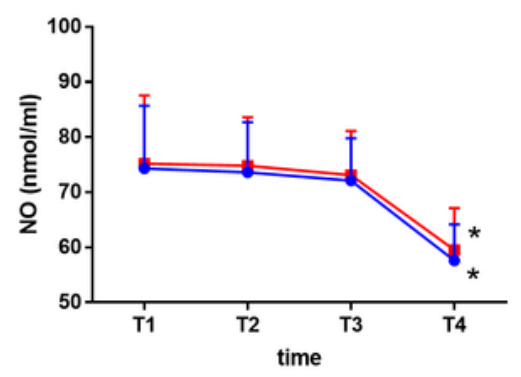

E

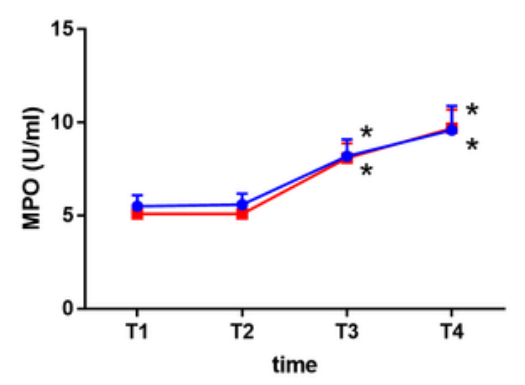

- Group C

- Group T

- Group C

- Group T

G

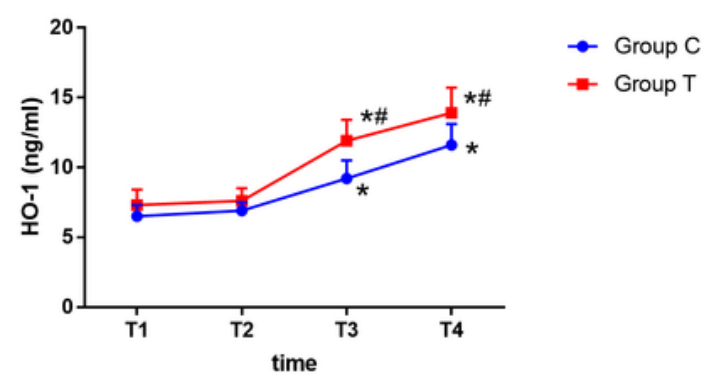

B

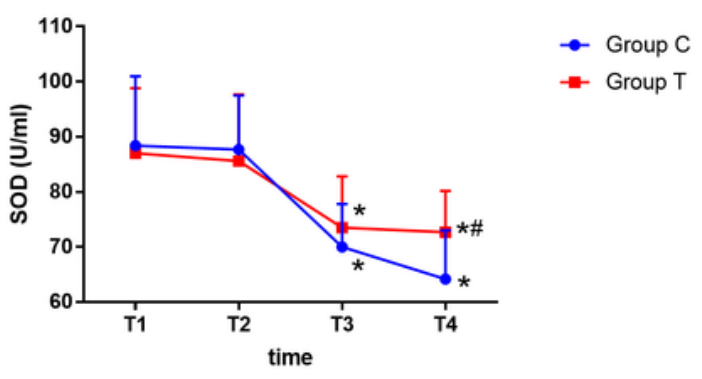

D

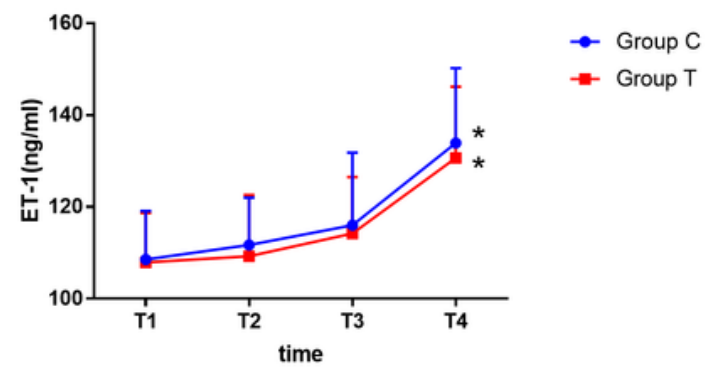

$\mathbf{F}$

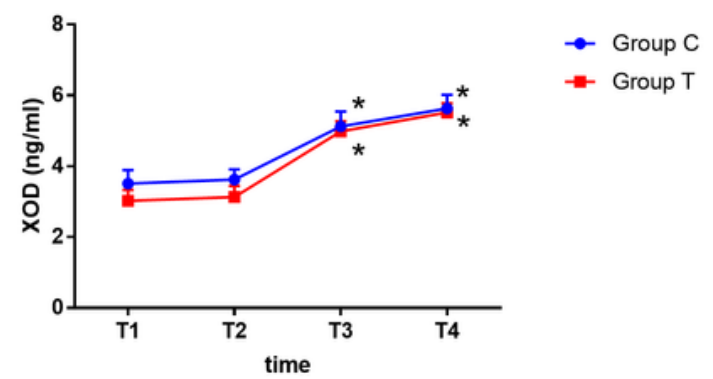

\section{Figure 4}

Changes of biomarkers in TEAS group and control group over time. Changes in (A) MDA(malondialdehyde), (B) SOD(superoxide dismutase), (C) NO(nitric oxide), (D) ET-1 (endothelin-1), (E)MPO(myeloperoxidase), (F)XOD (xanthine oxidase) and (G)HO-1(heme oxygenase-1) levels in transcutaneous electrical nerve stimulation (TEAS) group (Group T) and control group (Group C). 
Immediately before removing the tourniquet(T1), $30 \mathrm{~min}(\mathrm{~T} 2), 2 \mathrm{~h}(\mathrm{~T} 3)$ and $4 \mathrm{~h}(\mathrm{~T} 4)$ after removing the tourniquet. ${ }^{*} \mathrm{P}<0.05$, as compared to $\mathrm{T} 1, \mathrm{AP}<0.05$ as compared to group $\mathrm{C}$

A

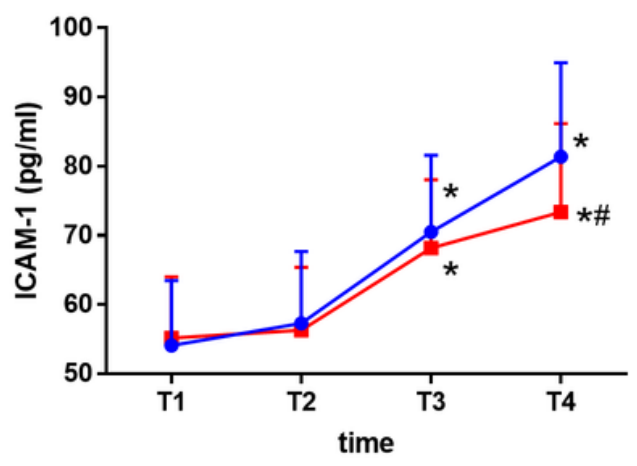

C

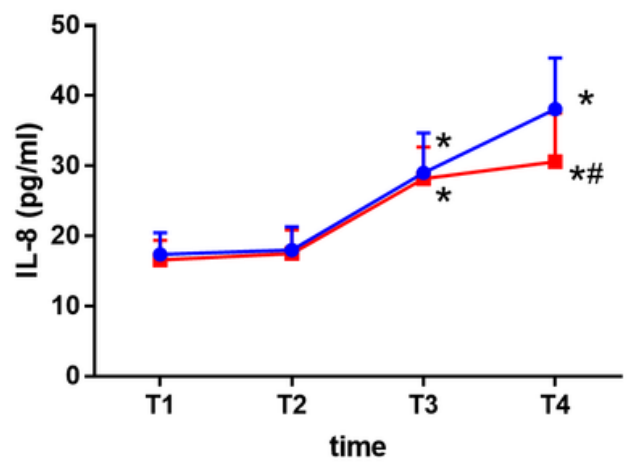

$E$

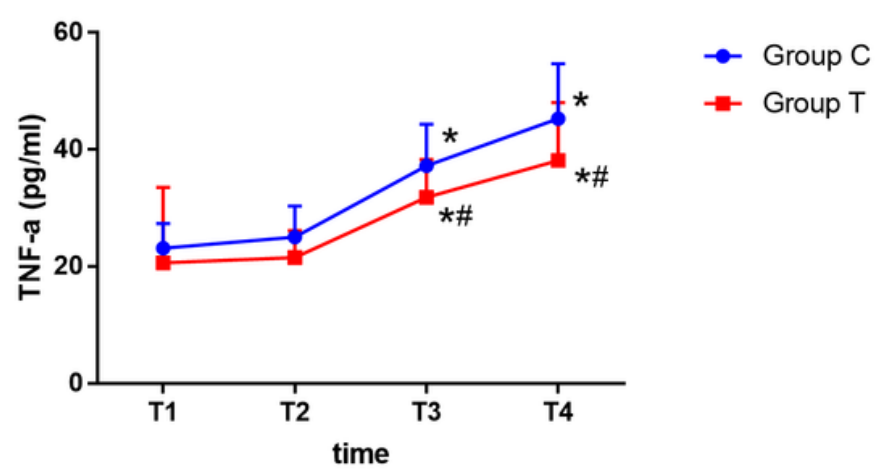

B

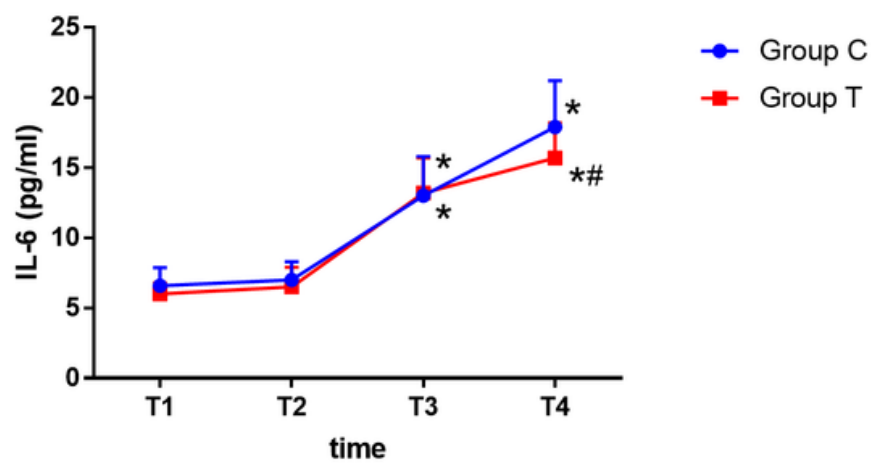

D

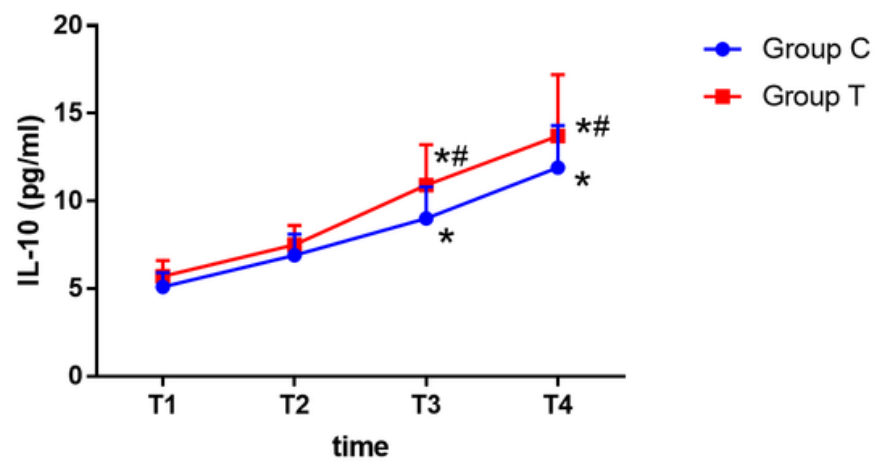

\section{Figure 5}

Changes of proinflammatory cytokine over time. Changes in (A) ICAM-1(intercellular adhesion molecule1), (B)IL-6 (interleukin-6) (C)IL-8(interleukin-8) (D)IL-10 (interleukin-10) and (E)TNF-a (tumor necrosis factor-a) in transcutaneous electrical nerve stimulation (TEAS) group (Group T) and control group (Group C). Immediately before removing the tourniquet(T1),30 $\mathrm{min}(\mathrm{T} 2), 2$ (T3) and $4 \mathrm{~h}(\mathrm{~T} 4)$ after removing the tourniquet. ${ }^{*} \mathrm{P}<0.05$, as compared to $\mathrm{T} 1 ; \mathrm{AP}<0.05$ as compared to group $\mathrm{C}$. 